\title{
Modelling Livestock Activities and Environmental Sustainability: The African Case
}

\author{
Eisa Abdalla Abdelgalil ${ }^{1}$, Suleiman Ibrahim Cohen $^{2}$ \\ ${ }^{1}$ Economic Research Department, Dubai Chamber of Commerce and Industry, Dubai, UAE; ${ }^{2}$ Erasmus School of Economics, Eras- \\ mus University Rotterdam, Rotterdam, the Netherlands. \\ Email: eisa.abdelgalil@dubaichamber.ae,cohen@ese.eur.nl
}

Received January $20^{\text {th }}, 2010$; revised February $28^{\text {th }}, 2010$; accepted March $1^{\text {st }}, 2010$.

\begin{abstract}
This paper develops a dynamic model of grazing land degradation. The model illustrates the relationship between livestock levels and grazing land degradation over time. It identifies the mechanisms by which the factors internal to the livestock local production system and those drawn from the larger economic context of livestock marketing influence livestock-grazing land relationship. The paper shows that overstocking leads to degradation which leads to declining relative prices of livestock as quality declines and mortality increases. As relative price of livestock falls, consumption increases. The increased consumption and mortality ultimately leads to lower livestock population, which leads to decreased degradation. The model results show that medium term dynamics of grazing land degradation are quite different from long term dynamics. It is shown that although grazing land sustainability situation is adverse in the medium term, yet it is favourable in the long term. The livestock system is dynamic and can adjust when longer term system dynamics are allowed to play out. Part of the adjustment mechanism is built in the livestock system and the other part comes from the economic system. The built-in adjustment mechanism works through the two-way relationship between the stock and degradation. The external adjustment mechanism, originating from the economic system, works through economic growth, relative prices and foreign trade. In the medium term, opportunistic management strategy and policies that facilitate access to grazing land and water are crucial for mitigating degradation. The results suggest that the views of the mainstream range management paradigm and the new thinking of range ecology can be reconciled.
\end{abstract}

Keywords: Livestock, Grazing Land, Degradation, Models

\section{Introduction}

There are complex relationships between livestock grazing and production on the one hand, and environment conservation and degradation costs on the other hand. In the context of the interaction between livestock and the environment in developing countries, several studies have underlined the tendency of overstocking of grazing land resulting in land degradation, see [1-4].

The degradation of grazing land adversely affects the natural growth rate of the livestock and its quality. When grazing land is degraded, the stock fertility rate falls and mortality rate rises, the weight of animals in terms of kilograms is less and the quality of their product is low, as compared to the situation where there is no degradation. Also, when grazing land is degraded its value falls. Furthermore, the decline in the livestock, both in quantity and quality, and the fall of the value of grazed land, lead to the decline of the capital wealth of the livestock sector [5-8].

The empirical literature on the analysis of the trade-off between livestock and environment and its economic implications is very sporadic. There is no more than a handful quantitative models that have addressed related issues. Wilcox and Thomas [9] used for Australia a model to examine the relationship between cost of production and range conditions under long term steadystate conditions. Braat and Opschoor [10] developed for Botswana a simulation model that focused on the role of rainfall and the stocking rate in determining the quality of the range and herd development. Berrings and Stern [11] using the cattle-rangeland system in the semi-arid rangelands of Botswana, followed a dynamic econometric approach for modelling the loss of resilience in an ecological-economic system.

None of the above quoted research encroached on formalising and modelling the complex relationship between the various aspects of livestock activities and the varied dimensions of environmental degradation. In this paper, we develop a simple and at the same time a comprehensive model in nine equations, that examines the medium and long terms dynamics of grazing and degra- 
dation in an African country, i.e. Sudan, where in relative terms, livestock activities take significant proportions. The importance of the model is that it synthesizes the views of the mainstream range management paradigm with the new range ecology thinking. The pursued model integrates the ecological and economic dimensions of the livestock system and the ecological system; these are elements that are mostly missing in the literature. Empirical data from Sudan are employed to operationalise the model, and investigate the complex relationships and their analytical and policy implications.

The paper proceeds as follows. Section 2 specifies the model. Section 3 discusses its structure. Section 4 deals with estimation and solution. Section 5 discusses the model results for the medium term scenario over the period 1990-2000, when livestock prices tended to fall in relative terms. Section 6 discusses model results for a long term scenario extending to 2030 , where livestock prices are assumed to remain stable in relative terms. Section 7 examines sensitivity results, and Section 8 concludes.

\section{Model Specification}

We formulate a determinate model of nine equations that focuses on giving solutions to nine crucial variables that link livestock activities and land degradation to each other.

To start with, we denote the actual number of animal stock that grazes on the available grazed land, by $L$. Next to the actual grazing capacity, any grazing land can be said to have an optimal carrying capacity for animals. The optimal carrying capacity refers to the number of animals that grazing land can support without being degraded. The word 'optimal' is used here in the agronomical sense of the word. The optimal carrying capacity of grazing land is determined by its size, $N^{1}$, its annual vegetation yield per unit of land, $V$, and the vegetation requirement per animal unit, $H$. When the actual capacity exceeds the optimal capacity, land degradation sets in. This idea is formalised in Equation (1), where the numerator gives the actual capacity, i.e. actual stock of animals, and the denominator gives the optimal capacity, i.e. desirable stock of animals on grazing land.

$$
Q=\left[\frac{L}{(V N) / H}\right]_{t-1} \quad Q \geq 1
$$

In Equation (1), the ratio of the actual capacity to the optimal one is used as an indicator of the prevailing conditions on grazing land. This ratio is a degradation index denoted by $Q$. The one-year lag of the variables is justified on the ground that it is the cumulative degradation from last year that adversely affects the current year variables.

\footnotetext{
${ }^{1}$ The land unit used here is the feddan which is a measure of area and it is equivalent to 4200 square metres or 0.42 acre.
}

When the actual capacity exceeds the optimal one, the degradation index exceeds unity. Ideally, the actual capacity should approach the optimal one. The situation when this is reached, i.e. $Q=1$, will be seen that the structure of the model will have to undergo changes that will be treated in a later section. The situation where $Q$ is below unity, a process of grazing land and livestock regeneration sets in, is not a focus of the paper.

According to Scoones [4] an effective management strategy of $Q$ can be achieved in four ways: 1) increasing available fodder by enhancing its production or importing feed from elsewhere; 2) moving livestock to where fodder is available; 3 ) reducing animal feed intake during drought through shifts in watering regimes; 4) destocking animals through sales during drought. It can be seen from Equation (1) that effective tracking is a good strategy that can pre-empt or reduce grazing land degradation. This is because increasing availability of fodder means increasing $V$; moving animals to where fodder exists means effectively expanding $N$; reducing animal feed intake means decreasing $H$; and destocking animals means reducing $L$. All these four options lead to lower $Q$, or in other words, less grazing land degradation.

Two of the four variables in the equation defining $Q$ are exogenously given; these are land $N$ and vegetation requirements $H$. The other two variables of $V$ and $L$ are endogenous and their determination is displayed below in additional equations.

The development of the vegetation yield of grazing land, $V$, depends on three main factors: rainfall water, Wrain, irrigation water ${ }^{2}$, Wirr, and degradation of grazing land, $Q$. The influence of the abovementioned three factors on vegetation yield is formalised in Equation (2). $V$ is positively related to the first two factors and inversely related to the third one. Given availability of rain and irrigation water, the expected vegetation yield will depend on the base year vegetation yield, $v_{0}$, and on the level of degradation of grazing land, as indicated by the ratio of the degradation index in the base year $Q_{0}$ to that of the current year $Q$, and an elasticity parameter $\eta$.

$$
V=\frac{v_{0}}{\left(Q / Q_{0}\right)^{\eta}}\left(W_{\text {rain }}\right)^{\alpha}\left(W_{\text {irr }}\right)^{\beta}
$$

The other variable to model is the size of the animal stock on grazing land ${ }^{3}$ in the current year, $L$. This is determined by last year's stock, $L_{t-1}$, the natural growth rate, $\mathrm{g}$, and the slaughter from the stock, which is equivalent to sale of livestock units of standard weight and quality at a given price. $X$ denotes the monetary value of live-

\footnotetext{
${ }^{2}$ The term "irrigation water" is used here in its broad sense to refer to underground water from dug wells as well as water from irrigation canals. ${ }^{3}$ Consideration is given here to four types of animals, namely, goats, sheep, cattle and camels. This is because mainly these animals are consumed and exported. Then, these animals are converted into livestock units (LSU) using the following livestock unit conversion factors: sheep and goats at 0.12 , cattle at 0.75 and camels at 1.00 [12].
} 
stock slaughter or output and $P$ is the price per unit of livestock. $P$ is constructed in such a way that it consists of the absolute price level per unit of livestock in the base year multiplied by the relative price index of livestock product to that of the alternative agricultural product $^{4}$.

Not only the natural growth rate but also the weight and the quality of livestock units are influenced by the prevailing conditions on grazing land. Therefore, both the growth rate of the stock and the price of livestock units have to be adjusted to reflect the condition prevailing on grazing land. This is formalised in Equation (3). The growth rate of the stock is adjusted for the prevailing conditions on grazing land by the ratio of the degradation index in the base year $Q_{0}$ to that of the current year $Q$, with elasticity parameter $\eta$. The price per unit of livestock $P$ is adjusted to reflect the prevailing conditions on grazing land by the ratio $Q_{0} / Q$. The idea is that in any given year a degradation level which is more (less) than that of the base year level means lower (higher) weight and quality of the sold livestock units in that year as compared to the base year. Therefore, the price of livestock units is adjusted accordingly, downward when there is more degradation and upward when there is less degradation relative to that of the base year.

$$
\begin{gathered}
L=L_{t-1}\left[1+g\left(\frac{Q_{0}}{Q}\right)^{\eta}\right]-\left[\frac{X}{\left(Q_{0} / Q\right) P}\right] \\
0<g, \eta<1
\end{gathered}
$$

The slaughter, i.e. the value of livestock output, is used for intermediate consumption and domestic final consumption, and is exported ${ }^{5}$. This is formalised in the sectotal balance Equation (4), where the left hand side of the equation gives the supply side and the right hand side gives demand side, both in monetary value. The intermediate deliveries are a proportion, $a 1$, of the country's gross domestic product, GDP. The final consumption demand for livestock product is a function of the GDP, and the relative price index of livestock product to that of the alternative agricultural product, denoted by $P_{\text {index }}$, where $\varepsilon, \gamma, \delta$ are parameters describing the final consumption demand. The livestock net exports, denoted by $E$, are fixed exogenously through the world demand and they are assumed to grow annually by a constant rate.

\footnotetext{
${ }^{4}$ The price per unit of livestock $\mathrm{P}$ can be written as $P_{0} P_{\text {index }}$, where $P_{0}$ is the absolute price level per unit of livestock in the base year and $P_{\text {index }}$ is the relative price index of the livestock product to that of the alternative agricultural product.

${ }^{5}$ Meat is the only product of the livestock sector that is considered here. Other products that are not directly relevant to the problem at hand, such as milk and hides, are not treated in this model.

${ }^{6}$ It is noted that whether land is allocated to grazing or other alternative uses such cultivation or forestry, depends on the relative value of land in its different uses, but since these alternative uses are not modelled here it is assumed that land allocated to grazing is fixed exogenously.
}

$$
\begin{gathered}
X=a 1(G D P)+\varepsilon(G D P)^{\gamma}\left(P_{\text {index }}\right)^{\delta}+E \\
0<\varepsilon, \gamma<1, \delta<0
\end{gathered}
$$

In Equation (5), the gross value added of the livestock sector, denoted by $Y$, is the value of the livestock offtake or output $X$ less the value of the intermediate inputs used for producing this output, assumed as a proportion $a 2$ of $X$.

$$
Y=(1-a 2) X
$$

In Equation (6), livestock output per unit of land in volume terms, $O$, is defined as total value of output $X$, divided by the price per unit of output and land, $P$ and $N$ respectively.

$$
O=\frac{X}{(P N)}
$$

In Equation (7), the value of a piece of land in the livestock sector $Z$ is derived from the return to that land. The return to a unit of grazing land is its share $b$, in the value of output $P O$, adjusted for the level of grazing land degradation by the factor $Q_{0} / Q$. The adjustment factor $Q_{0} / Q$ reflects the adverse impact of degradation on the value of land, and the effect is assumed to be proportionate. ${ }^{6}$

$$
Z=b P O\left(\frac{Q_{0}}{Q}\right) \quad 0<b<1
$$

In Equation (8), the wealth value of the livestock sector, $R$, is defined to comprise the total value of grazed land, that is the grazed land $N$ multiplied by the unit value of grazed land, $Z$, and the value of the stock of animals on that land. Degradation will affect the wealth of the sector $R$ not only via a diminished land price $Z$ as occurs in the previous equation, but also via a diminished livestock price $P$ as in the current equation. To allow for the degradation effects on $P, Q / Q_{0}$ is incorporated as an adjustment factor that reflects the prevailing conditions on grazing land. A proportionate effect of degradation on price is assumed.

$$
R=Z N+L\left(\frac{Q_{0}}{Q}\right) P
$$

Finally, returning to the degradation index, any rise in $Q$ implies additional degradation costs. When grazing land is degraded, it has to be reclaimed if production is to be sustained into the future. The reclamation cost of degraded grazing land can be thought of as the depreciation cost of production in the livestock sector. Being as such, a depreciation allowance should be set aside for financing the reclamation of degraded land. This is called here degradation cost, and is denoted by $D$. It is defined in relation to the desirable value of $Q=1$, where there is no grazing land degradation. The average reclamation cost for a piece of land, denoted by c, has been estimated at ten per cent of the foregone output of that land as a result 
of its degradation [13]. The foregone output of land is the lost output share of the factor of production land, $b O$, valued at the price $P$. The output loss is dependent on the degradation level $(1-1 / Q)$. Degradation cost per unit of land is then multiplied by $\mathrm{N}$ to give $D$, as formalised in Equation (9).

$$
D=c(b P O)\left(1-\frac{1}{Q}\right) N
$$

If $Q$ is at its desirable level of 1 , i.e. when the actual stock of animals is commensurate with the grazing land carrying capacity, the degradation cost becomes zero. See Section 6 for treating the model under the situation when $Q=1$.

\section{Model Structure}

Causal ordering (or recursivity) is used to understand the structure of the model. Causal ordering has been mainly elaborated in Simon [14]. As shown in Table 1, the livestock model has a simple diagonal structure containing four orders, and a total of nine equations that are solved for nine endogenous variables. These endogenous variables are $D, L$, $O, Q, R, V, X, Y, Z$. In the 1st order, which contains Equations (1) and (4), two endogenous variables are determined. These are grazing land degradation index $Q$ and output value of the livestock sector $X$. In the 2nd order, which contains Equations (2), (3), (5) and (6), four endogenous variables are determined. These are vegetation yield per unit of grazing land $V$, stock of animals $L$, income of livestock sector $Y$ and output per unit of grazing land $O$. In the 3rd order, which contains Equation (7), the per unit value of land $Z$ is determined. In the $4^{\text {th }}$ order, which contains Equations (8) and (9), two endogenous variables are determined, these are wealth $R$ and degradation cost $D$. Note furthermore in Table 1, that Equations (2), (3), (5) and (6) are in a higher order than Equations (1) and (4), but they are in a lower order than Equations (7), (8) and (9).

As it is clear from the model structure, the most crucial variable in the model is the degradation index $Q$.
The degradation index influences the vegetation yield per unit of land $V$, stock of animals $L$, value per unit of land $Z$, wealth $R$, and depreciation cost $D$ in livestock sector.

\section{Estimation and Solutions of the Model}

The model is calibrated for Sudan for the base year 1990. This year is chosen as the base year because it has marked the beginning of a major economic reform programme in the country. Several sources are used in estimation of the parameters, see appendix Table 3. Estimates of most behaviourally oriented parameters, denoted by small Greek letters, were calibrated from the Social Accounting Matrix (SAM) of Sudan [15]. Estimates of most physically oriented parameters, denoted by small Latin letters, came from livestock literature. The exogenous variables are taken from publications of the Ministry of Agriculture, Ministry Finance and the Department of Statistics of Sudan; see appendix Table 4.

Estimates of parameters and exogenous variables for the base year are fed into the model and solved to reproduce the observed values of the endogenous variables in 1990. The model is then solved under varying assumptions for two scenarios: a) the medium term of 1990 2000 with falling relative livestock price, reflecting the actual past developments, and (b) the long term, extended from 1990 to 2030 , with stable relative livestock prices.

As the model contains mechanisms with time lags, the model results can be expected to show up recurring cycles over time for the crucial variables of the size of livestock, $L$, measured in ten millions of equivalent animal units, and the index of degradation, $Q$. Indeed, these cycles occur, as is shown in Figure 1 below.

As the recurring cycles occur already within the ten year period of 1990-2000, it becomes interesting to examine in the long term scenario the characteristic properties of the relationship between livestock and

Table 1. Model structure

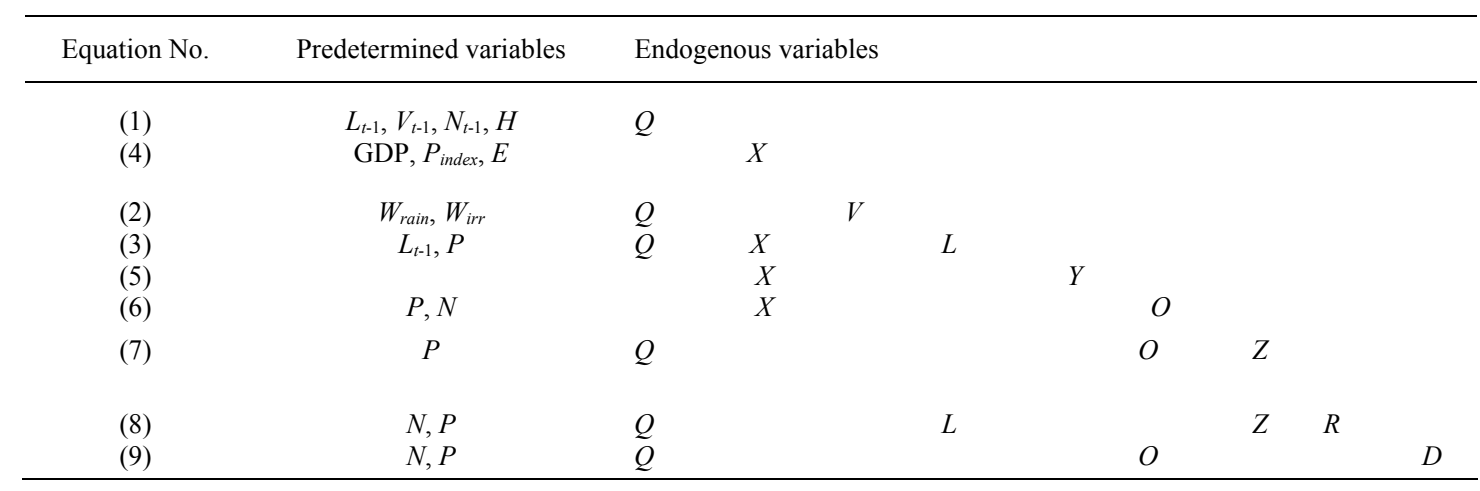




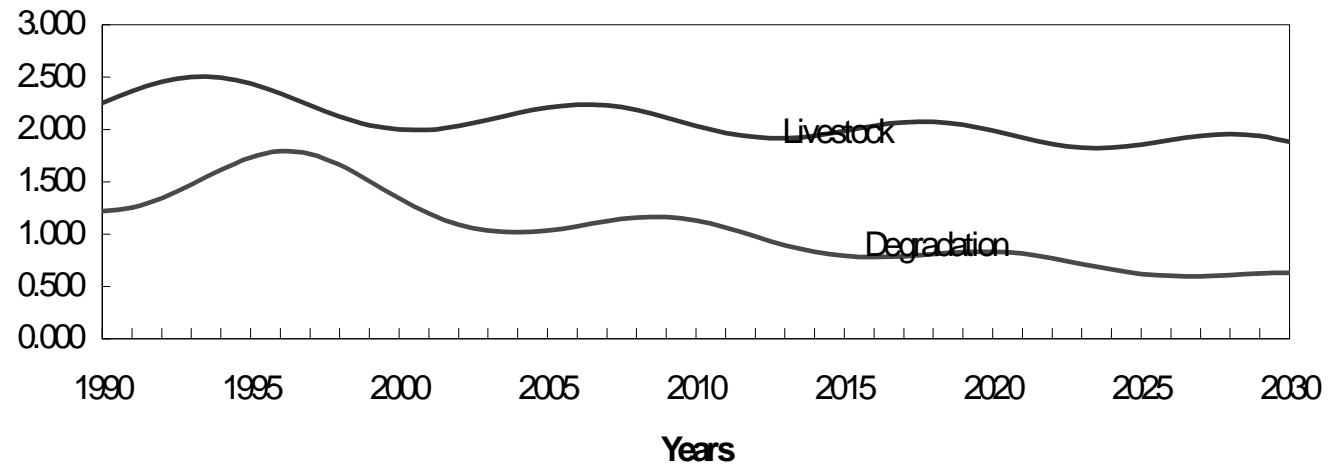

Figure 1. Livestock in ten millions of equivalent units, and degradation index, 1990-2030

Table 2. Projected scenarios of the model: Medium term and long term

\begin{tabular}{|c|c|c|c|c|c|c|c|c|c|}
\hline \multirow{2}{*}{ Symbol } & \multirow{2}{*}{ Description } & \multirow{2}{*}{$\begin{array}{c}\text { Measure } \\
\text { ment }\end{array}$} & \multirow{2}{*}{$\begin{array}{l}\text { Value } \\
1990\end{array}$} & \multicolumn{2}{|c|}{$\begin{array}{l}\text { Medium term: Falling } \\
\text { relative price of livestock }\end{array}$} & \multicolumn{4}{|c|}{$\begin{array}{l}\text { Long term: Stable relative price } \\
\text { of livestock, i.e. } P_{\text {index }}=1.0\end{array}$} \\
\hline & & & & $\begin{array}{c}\text { Growth } \\
\% \text { p.a }\end{array}$ & $\begin{array}{l}\text { Value } \\
2000\end{array}$ & $\begin{array}{c}\text { Growth } \\
\% \text { p.a }\end{array}$ & $\begin{array}{l}\text { Value } \\
2000\end{array}$ & $\begin{array}{l}\text { Value } \\
2012\end{array}$ & Value 2030 \\
\hline$D$ & Degradation cost & Billion Ls & 0.105 & 3.078 & 0.142 & 4.502 & 0.163 & 0.000 & 0.000 \\
\hline$L$ & $\begin{array}{l}\text { Livestock in } \\
\text { equivalent units }\end{array}$ & Ten Million & 2.2524 & -1.338 & 1.9686 & -1.192 & 1.9978 & 1.9255 & 1.8831 \\
\hline$O$ & Output per feddan & $\operatorname{LSU}^{(\mathrm{c})}$ & 0.033 & 0.976 & 0.037 & 0.952 & 0.037 & 0.061 & 0.060 \\
\hline V & Vegetation yield & Metric Ton & 1.067 & -0.412 & 1.024 & -0.760 & 0.989 & 1.275 & 1.275 \\
\hline$Q$ & Degradation index & Index & 1.220 & 0.518 & 1.285 & 0.958 & 1.342 & 1.000 & 1.000 \\
\hline$R$ & Total wealth & Billions Ls & 88.426 & -1.679 & 74.651 & -1.977 & 72.421 & 81.298 & 79.505 \\
\hline$X$ & Total output & Billion Ls & 9.409 & 0.976 & 10.369 & 0.952 & 10.344 & 17.287 & 16.906 \\
\hline$Y$ & Sectoral GDP & Billion Ls & 7.762 & 0.976 & 8.554 & 0.952 & 8.534 & 14.262 & 13.948 \\
\hline$Z$ & Land value & Thousand Ls & 0.075 & 0.456 & 0.079 & -0.006 & 0.075 & 0.139 & 0.135 \\
\hline$E$ & Exports value (a) & Billion Ls & & & & & & 4.642 & -12.647 \\
\hline \multicolumn{10}{|c|}{ Sustainability indicators } \\
\hline$D / X$ & Deg. per unit of $X$ & Ls & 0.011 & 2.081 & 0.014 & 3.517 & 0.016 & 0.000 & 0.000 \\
\hline$D / Y$ & Deg. per unit of $Y$ & Ls & 0.013 & 2.081 & 0.017 & 3.517 & 0.019 & 0.000 & 0.000 \\
\hline$Y-D$ & Green GDP & Billion Ls & 7.657 & 0.945 & 8.413 & 0.895 & 8.371 & 14.262 & 13.948 \\
\hline
\end{tabular}

(a) Exports, $E$, is exogenous in the original structure of the model, and that is why no value is entered for $E$ for the years 1990 and 2000 in Table 2, but the exogenous value for $E$ is provided in the appendix Table 4. However, in the long term (i.e. from the year 2012 and on) the model structure is changed so that exports, $E$, become endogenous. For more elaboration of this point see Section 6.

degradation over a longer period up to 2030. Running the long term scenario will also highlight the long range future outlook for the livestock sector and its environmental repercussions, which are relevant for policy making.

It is worth mentioning that the model is more analytical than predictive. Therefore, the focus is more on trends and tendencies in the medium and long runs, rather than on exact magnitudes of the modelled variables. Therefore, the results should be read in that light. The next sections will analyse the results of the medium and long term scenarios, which are summarized in Table 2.

${ }^{7}$ It is estimated that the price of livestock product is growing by an annual rate of $4.2 \%$ while that of the alternative agricultural product by $4.8 \%$. Therefore, the relative price of livestock product is falling by an annual rate of $0.6 \%$.

\section{The Medium Term Scenario: Falling Relative Livestock Prices}

In the medium term scenario, a period of ten years until 2000 , it is assumed that the gross domestic product, GDP, and intermediate deliveries from livestock sector to the rest of the economy, grow annually by $5 \%$, livestock exports $E$ to grow annually by $3 \%$, and the relative price index of livestock product $P_{\text {index }}$ to fall annually by $-0.6 \%{ }^{7}$. These are the average growth rates of these variables during the period of 1990-2000.

Table 2 gives the results for the medium term scenario. The fall of the relative price of livestock product leads to more consumption of livestock product and hence livestock $L$ falls by $1.338 \%$ annually. This compares to a fall of $1.192 \%$ in the second scenario. The difference is due to the falling price of livestock product relative to that of 
the alternative agricultural product. With the relative price of livestock product falling, more livestock product is consumed and therefore livestock is relatively falling faster than when its relative price is unchanging.

As a result, degradation index $Q$ rises by $0.518 \%$ in the first scenario as compared to $0.958 \%$ in the second scenario. Correspondingly, vegetation yield $V$ falls annually by $0.412 \%$ in the first scenario and by $0.760 \%$ in the second scenario. Both output $X$ and income $Y$ grow by $0.976 \%$ in the first scenario and by $0.952 \%$ in the second scenario. The value of land $Z$ grows by $0.456 \%$ in the first scenario, but declines marginally by $0.006 \%$ in the second one. Regarding degradation $\operatorname{cost} D$, it rises at a rate of $3.078 \%$ under the first scenario, but at a rate of $4.502 \%$ under the second one.

The above brief discussion of the model medium term results show that grazing land sustainability situation is adverse in the medium term. But as we will see in the next section, this situation is quite favourable in the long term. This is because the livestock system has sufficient time to adjust when longer term livestock system dynamics are allowed to play out.

\section{The Long Term Scenario: Stable Relative Livestock Price}

In the long term scenario, the same assumption of 5\% growth of GDP and intermediate deliveries are held, livestock exports $E$ are endogenized after 2000, and most importantly, we assume an unchanging relative price of livestock products. This is justified by 1) the uncertainty about the trends of relative prices over such a long period of time, and 2) a stable price represents a conservative prospects for the sector whose achievement can be seen to be always more plausible than that of a rising price and a booming prospects.

The results for the long term scenario, Table 2, show falling livestock $L$ and declining degradation $Q$. These occur in more or less equivalent waves of ups and downs in the direction approximately indicated by a ten-year period ${ }^{8}$. The long term falling trend of livestock is explained by the outcome that both the slaughter from the stock and the cyclical rise of grazing land degradation are favouring the reduction of the stock. The long term declining trend of grazing land degradation is caused by the falling trend of livestock. The sequence of causation, in this two-way rela-

\footnotetext{
${ }^{8}$ Such cycles in livestock dynamics are also confirmed by Fafchamps. According to Fafchamps "Although the timing of cycles depends on exogenous rainfall shocks, it fundamentally results from the accumulation of animals beyond the carrying capacity of the range", [16].

${ }^{9}$ For nomadic livestock owners in Sudan, animals are a store of food and wealth in addition to their socio-cultural role. Therefore, they would not allow this joint store of food and wealth, and socio-cultural symbol, to fall below a certain level [12].

${ }^{10}$ It is interesting to note that in Western Australia, [9] found that this ratio, which they called the ratio of turnoff to herd size, is more than 0.200 in areas where the range conditions are good.
}

tionship between the stock and degradation, runs from the stock to degradation and then from degradation to the stock. This can be seen from Figure 1, where the peak of the stock precedes that of the degradation.

The figure shows that the long term declining trend of livestock is less pronounced than its medium term declining trend. Note that while degradation is rising in the medium term when compared to the base year level, yet it is falling in the long term. This is because the impact of the forces at work in the model is not fully realised in the medium term. In the long term, the impact of these forces is fully realised since there is sufficient time for the livestock system to adjust.

The sustainability situation of grazing land is favourable as degradation is declining. This is because the offtake from the stock is increasing. This increase in the offtake is due to economic growth, rising income and livestock exports, which all favour increased demand for livestock product.

Equation (1) of the model has the restriction that $Q \geq 1$. This is because once $Q$ falls blow 1 the livestock sector will be operating under grazing land conditions where there is no degradation and theoretically speaking a process of grazing land and livestock regeneration sets in, but this possibility is not discussed in this paper. In the long term projection of the model, $Q$ falls below unity starting in the year 2012. Therefore, $Q$ is kept at 1 during the period 2012-2030 according to the restriction of Equation (1).

When $Q$ reaches 1, the original structure of the model is bound to change into a new structure. With two variables $Q$ and $V$ becoming by definition exogenous, Equations (1) and (2) are practically dropped from the model.

In the absence of degradation, a very plausible scenario for livestock development, which at the same time gives justice to economic and socio-cultural considerations ${ }^{9}$, is to assume that livestock owners would like to maintain a stable balance between the off-take and the stock. In this way, slaughter as a proportion of the stock assumes a certain ratio $\psi$, see Equation (10) below. This ratio can be fixed at the point where the livestock is operating under the grazing land conditions where there is no degradation, which is when $Q$ reaches 1 . This occurs in the year 2012 and at this point the ratio of slaughter to stock, $\psi$, is about $0.245 .^{10}$

$$
\left(\frac{X}{P}\right) / L=\psi
$$

With this one additional equation, the solution of the model requires that one additional variable should become endogenous. In the new model structure, it is proposed that net exports of livestock, $E$, which is exogenous in the original structure of the model, becomes endogenous.

The three main equations of the restructured model (3), (4) and (10) contain three endogenous variables, 
namely $L, X$ and $E$. These equations are solved simultaneously and the results are used for solving the rest of the model.

The solution of the endogenous variables under the new structure of the model for the year 2012 and the year 2030 are presented in the last two columns of Table 2. Note that livestock exports $E$ are added to Table 2 as an endogenous variable for the years 2012 and 2030. But before the year 2012, $E$ was exogenous and that is why it is not shown in Table 2 before 2012. As can be seen from the table, degradation cost $D$ is zero in 2012 and 2030 , since degradation index $Q$ is unity in these two years. The output $X$ in 2030 is somewhat less than that in 2012. Therefore, the domestic output, which is used to meet domestic consumption demand, is supplemented in later years by imports of livestock product, i.e. net exports $E<0$, see Table 2 . This is explained by the outcome that our assumption of unchanging relative price of livestock product has ruled out any price adjustment mechanism. Therefore, a quantity adjustment mechanism has to adjust supply to rising demand, and the net exports of livestock product $E$ has to bear the burden of this adjustment, see Equation (4) of the model.

The above analysis shows that there are two adjustment mechanisms at work in the long term. The first one is internal to the livestock sector and the second one is external. The internal one shows that the livestock system is self-regulatory in the sense that it has a built-in adjustment mechanism. This mechanism works through the two-way relationship between the stock and degradation. When the stock of grazing animals exceeds grazing land carrying capacity degradation sets in. Due to degradation the stock does not continue to grow steadily and sustainably, since degradation adversely affects the growth of the stock. After a certain point in time, the stock is adjusted downward to the prevailing degradation conditions on grazing land. The end result is that the downward adjustment of the stock eases the pressure on grazing land and hence degradation is mitigated.

The external adjustment mechanism originates from the economic system and it works through economic growth, foreign trade and relative prices. We have seen the last one in the medium term analysis and in principle it applies also for the long term ${ }^{11}$. Rising income, falling relative price of livestock product and more livestock exports lead to increasing off-take from the stock which eases pressure on grazing land and ultimately reduces

\footnotetext{
${ }^{11}$ In the long term solution of the model and under changing relative prices scenario (not reported here), the livestock system reaches the point of no degradation, i.e. $Q=1$, in much earlier time than under the unchanging relative prices scenario, which we have seen here.

${ }^{12}$ The term (dis) equilibrium is used in ecology to refer to an ecosystem where populations are in long term (im) balance with other elements of the system [17].

${ }^{13}$ An IMF working paper shows that lower price of meat in Sudan leads to more off-take from the stock since livestock owners want to supplement their income and smooth consumption [18].
}

degradation.

The results of the model suggest that it is possible to reconcile the new range ecology thinking $[4,17,19]$ with that of the mainstream range management paradigm. The latter, which assumes equilibrium ${ }^{12}$ environment, argues that the number of animal population is limited by availability of vegetation and the existence of excessive number of animals on the range adversely affect vegetation and this leads in the long run to rangeland degradation. The former, which assumes disequilibrium environment, argue that both animal population and vegetation are dominated by external factors such as rainfall and animal population are kept low by events such as drought and therefore animal population cannot have long run adverse impact on rangeland. The model results in the medium term seem to confirm the mainstream range management thinking while the model results in the long term seem to confirm the new range ecology thinking. Thus, whether range ecology is in equilibrium or disequilibrium is not a permanent situation but a situation that varies over time. Therefore, it appears that both paradigms, equilibrium and disequilibrium, have a grain of truth in their views regarding the issue of land degradation.

\section{More Discussion of Results}

The lower part of Table 2 sums up several sustainability indicators for the livestock sector. The sustainability situation is relatively encouraging under the scenario of changing relative prices as compared to the unchanging one. Under the first scenario, degradation cost per unit of output and value added, $D / X$ and $D / Y$ respectively, grow by $2.081 \%$ per annum, compared to $3.517 \%$ under the second scenario. Regarding the sectoral green GDP, $(Y-D)$, it grows by $0.945 \%$ under the first scenario and by $0.895 \%$ under second scenario. The concept of green GDP here refers to the livestock sectoral GDP, $Y$, after the deduction of the degradation cost of grazing land, $D$. The degradation cost is supposed to be deposited in separate fund for financing the reclamation of the degraded land in the livestock sector, if production is to be sustained into the future.

One important policy lesson which emerges from this discussion is that a falling relative price of livestock product encourages more consumption from the stock, thereby eases the pressure on grazing land and ultimately grazing land degradation is mitigated ${ }^{13}$. In other words, subsidising the price of livestock product can be a policy option for achieving sustainability in the livestock sector, but this needs to be weighed against any distortionary effects or fiscal problems that the subsidy may cause.

As an exercise in sensitivity analysis, the parameter $\gamma$ 
that describes the final demand function for livestock product has been increased by $5 \%$. For some variables such as the stock $L$ and degradation index $Q$, the projected trend has changed resulting in improved sustainability of grazing land. This indicates that a shift in consumers' preferences towards more consumption of livestock product promotes environmental sustainability in the livestock sector.

Furthermore, an opportunistic management strategy that involves an increase of vegetation yield $V$; effective expansion of grazing land $N$; reduction of animals vegetation intake $H$; and reduction of the stock $L$ can preempt or reduce grazing land degradation, that is resulting in lower $Q$.

\section{Conclusions}

Some important conclusions have emerged from the analysis. First, the livestock system is dynamic and can adjust when longer term system dynamics are allowed to play out. Part of the adjustment mechanism is built in the livestock system and the other part comes from the economic system. The built-in adjustment mechanism works through the two-way relationship between the stock and degradation. The external adjustment mechanism, originating from the economic system, works through economic growth, relative prices and foreign trade. Second, although grazing land sustainability situation is favourable in the long term, yet it is adverse in the medium term. Therefore, an external intervention in the form of appropriate policies, that facilitate access to grazing land and water, is needed to help the livestock system adjust in the medium term and mitigate degradation. Also, opportunistic management strategy on the part of pastoralists is an effective way of pre-empting and/or reducing grazing land degradation. The model results seem to suggest a reasonable synthesis of the traditional mainstream range management approach with the new range ecology thinking.

It is important to be reminded that the model is more analytical than predictive. Its focus is more on medium and long term trends rather than exact mangnitudes. Therefore its results should be understood in that light.

\section{REFERENCES}

[1] L. R. Oldeman, R. T. A. Hakkeling, and W. G. Sombroek, "World map of the status of human induced soil degradation: An explanatory note," ISRIC/UNEP, Wageningen, The Netherlands, 1991.

[2] H. Dregne, M. Kassas, and B. Rozanov, "Status of desertification and implementation of United Nations plan to combat desertification," Desertification Control Bulletin, No. 20, pp. 6, 1991.

[3] C. de Haan, H. Steinfeld, and H. Blackburn, "Livestock and the Environment: Finding a balance," Study sponsored by the European Commission, FAO and World Bank, 1997.

[4] I. Scoones, (Ed.) "Living under uncertainty: New directions in pastoral development in Africa," Intermediate Technology Publications, London, 1994.

[5] T. Amede, et al., "Maximizing benefits from livestockwater venture in Sub-Saharan Africa: From concepts to practices," The International Water Management Institute/ International Livestock Research Institute, Addis Ababa, Ethiopia, 2009.

[6] A. K. Acharya and N. Kafle, "Land degradation issues in Nepal and its management: Through agroforestry," The Journal of Agriculture and Environment, Vol. 10, June 2009.

[7] A. de Sherbinin, "CIESIN thematic guide to land-use and land-cover change," Center for International Earth Science Information Network (CIESIN), Columbia University, Palisades, NY, USA, 2002.

[8] G. B. Thapa and G. S. Paudel, "Evaluation of the livestock carrying capacity of land: Resources in the Hills of Nepal based on total digestive nutrient analysis," Agriculture, Ecosystems \& Environment, Vol. 78, No. 3, pp. 223-235, May 2000.

[9] D. G. Wilcox and J. F. Thomas, "The Fitzroy valley regeneration project in Western Australia," in J. A. Dixon, D. E. James and P. B. Sherman, Eds., "Dry management: Economic case studies," Earthscan Publications Ltd., London, 1990.

[10] L. C. Braat and J. B. Opschoor, "Risk in the Botswana range-cattle system," in J. A. Dixon, D. E. James and P. B. Sherman, Eds., "Dry management: Economic case studies," Earthscan Publications Ltd., London 1990

[11] C. Berrings and D. I. Stern, "Modelling loss of resilience in agroecosystems: Rangelands in Botswana," Environmental and Resource Economics, Vol. 16, No. 12, pp. 185-210, 2000.

[12] D. Pearce, E. Barbier, and A. Markandya, "Sustainable development: Economics and environment in the Third World," Edward Elgar, England, 1990.

[13] A. R. Gigengack, C. J. Jepma, D. MacRae, and F. Poldy, "Global modelling of dryland degradation," in J. A. Dixon, D. E. James and P. B. Sherman, Eds., "Dry management: Economic case studies," Earthscan Publications Ltd., London, 1990.

[14] H. A. Simon, "Causal ordering and identifiability," in W. C. Hood and T. C. Koopmans, Eds., "Studies in econometric method," Cowles Foundation Monograph, No. 14, Yale University Press, New Haven, 1953.

[15] E. Abdelgalil, "Economic policies for sustainable resource development: Models applied to Sudan," PhD thesis, Erasmus University Rotterdam, The Netherlands, 2000.

[16] M. Fafchamps, "The tragedy of the commons, livestock cycles, and sustainability," Journal of African Economies, Vol. 7, No. 3, pp. 384-423, 1998.

[17] J. Ellis, "Climate variability and complex ecosystem dynamics: Implications for pastoral development," in I. Scoones, Ed., "Living under uncertainty: New directions in pastoral development in Africa," Intermediate Technology 
Publications, London, 1994.

[18] R. Ramcharan, "Money, meat, and inflation: Using price data to understand an export shock in Sudan," IMF Working
Paper WP/02/84, 2002.

[19] R. H. Behnke, I. Scoones, and C. Kerwin, "Range Ecology at Disequilibrium," ODI, London, UK, 1993.

\section{Appendix}

Table 3. Parameters estimates

\begin{tabular}{clc}
\hline Symbol & Description & Value \\
\hline$\alpha$ & Effect of rainfall water on vegetation yield & 0.500 \\
$\beta$ & Effect of irrigation water on vegetation yield & 0.500 \\
$\gamma$ & Effect of GDP on consumption demand for livestock & 0.950 \\
$\delta$ & Effect of price on consumption demand for livestock & -0.100 \\
$\varepsilon$ & Average propensity of consumption demand for livestock & 0.029 \\
$\eta$ & Effect of degradation on livestock and vegetation & 0.800 \\
$a 1$ & Coefficient of intermediate deliveries by livestock sector to whole economy & 0.0073 \\
$a 2$ & Coefficient of intermediate deliveries received by livestock sector & 0.175 \\
$b$ & Share of factor land in value added of livestock sector & 0.617 \\
$c$ & Reclamation cost as a proportion of foregone output & 0.100 \\
$g$ & Average gross annual growth rate of the stock & 0.142 \\
\hline
\end{tabular}

Table 4. Exogenous variables (Ls=Sudanese pound)

\begin{tabular}{|c|c|c|c|c|}
\hline \multicolumn{2}{|c|}{ Symbol Description } & \multirow{2}{*}{$\begin{array}{c}\text { Measurement } \\
\text { Billion Ls }\end{array}$} & \multirow{2}{*}{$\begin{array}{l}1990 \\
2.352\end{array}$} & \multirow{2}{*}{$\begin{array}{c}\text { Growth p. a. } \\
0.030\end{array}$} \\
\hline$E$ & Value of livestock exports & & & \\
\hline$N$ & Total grazing land & Million feddan & 77.000 & \\
\hline$P$ & Price per livestock unit in the base year & Thousand Ls & 3.668 & \\
\hline$P_{\text {index }}$ & Relative price index of livestock product & Index & 1.000 & $-0.006^{(a)}$ \\
\hline$H$ & Vegetation requirement per livestock unit & Metric ton & 4.562 & \\
\hline$W_{\text {rain }}$ & Rainfall index & Index & 1.000 & \\
\hline$W_{i r r}$ & Irrigation index & Index & 1.000 & \\
\hline GDP & Gross domestic product of the whole economy & Billion Ls & 192.660 & 0.050 \\
\hline
\end{tabular}

(a) The model is also simulated assuming that $P_{\text {index }}$ is not changing, i.e. $P_{\text {index }}=1.0$ 